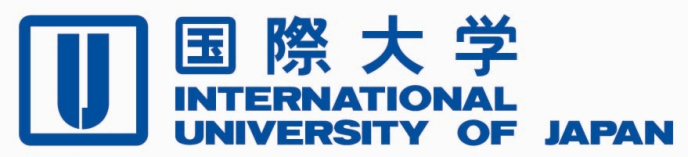

Economics \& Management Series

EMS-2010-14

\title{
Cyclical behavior of a matching model with capital investment
}

\author{
Hiroaki Miyamoto \\ International University of Japan
}

November 2010

IUJ Research Institute

International University of Japan

These working papers are preliminary research documents published by the IUJ research institute. To facilitate prompt distribution, they have not been formally reviewed and edited. They are circulated in order to stimulate discussion and critical comment and may be revised. The views and interpretations expressed in these papers are those of the author(s). It is expected that the working papers will be published in some other form. 


\title{
Cyclical Behavior of a Matching Model with Capital Investment*
}

\author{
Hiroaki Miyamoto ${ }^{\dagger}$ \\ International University of Japan \\ First Version: April 18, 2006 \\ This Version: October 22, 2010
}

\begin{abstract}
This paper studies the role of capital investment in a search and matching model. I develop an endogenous job separation matching model in which a firm's irreversible capital investment is endogenously determined. The incorporation of capital investment provides an additional channel for firms to respond to productivity shocks, significantly magnifying labor market fluctuations. The numerical results demonstrate that the incorporation of irreversible capital investment improves the ability of the standard search and matching model to generate cyclical fluctuations of unemployment and vacancies in response to productivity shocks. Moreover, my model can generate the pro-cyclicality of vacancies, which the standard endogenous separation models often fail to generate.
\end{abstract}

Keywords: Labor market search, Unemployment and vacancies volatility, Business Cycle, Capital investment.

JEL Classification: E24, E32, J63, J64

\footnotetext{
${ }^{*}$ I am grateful to Christopher L. Foote and two anonymous referees for very helpful comments and suggestions. I am also grateful to Morris A. Davis, Steven N. Durlauf, John Kennan, Rasmus Lentz, and James Walker for their invaluable comments and suggestions. I also thank Makoto Kakinaka, Rebecca Lessem, Ching-Yang Lin, John Morrow, Michael Rapp, Jiao Shi, Yoshimasa Shirai, Yuya Takahashi, Shintaro Yamaguchi and seminar participants at Search Theory Workshop at Kansai University for their helpful comments. All remaining errors are mine.

${ }^{\dagger}$ Mailing Address: International University of Japan, 777 Kokusai-cho, Minami Uonuma-shi, Niigata 949-7277 JAPAN. E-mail: hmiyamot@iuj.ac.jp
} 


\section{Introduction}

The Mortensen-Pissarides search and matching model (henceforth MP model) has become a standard framework for analyzing aggregate labor markets. However, the MP model has recently been criticized for its inability to explain key business cycle properties of the U.S. labor market (Costain and Reiter, 2008; Hall, 2005; Shimer, 2005). ${ }^{1}$ Shimer (2005) demonstrates that the MP model cannot generate the observed unemployment and vacancy fluctuations in response to reasonable shocks. Many solutions have been proposed to solve this problem. Some examples are wage rigidity (Hall, 2005; Shimer, 2005), different calibration strategies (Hagedorn and Manovskii, 2008), on-the-job search (Krause and Lubik, 2007; Nagypál, 2007; Tasci, 2006) and informational rents (Kennan, 2010).

In this paper, I incorporate capital investment into a search and matching model, finding that its inclusion improves the ability of the model to explain the cyclical volatility of unemployment and vacancies. Capital investment plays an important role over the business cycle. Firms' investment decisions affect whether they open new vacancies or shut down jobs. ${ }^{2}$ Therefore, incorporating capital investment seems to be a natural extension of the standard search and matching model.

I develop an endogenous job separation matching model in which a firm's capital investment decision is endogenously determined. In the model, when a firm meets a worker, the firm pays a capital installation cost and rents capital. A firm can increase its profit by adjusting its capital level, so capital investment influences the firm's job creation and separation decisions. The incorporation of capital investment amplifies the response of labor market variables to productivity shocks. A rise in productivity encourages firms to invest in more capital. The changes in capital have two effects. First, it further raises the productivity and motivates firms to post more vacancies. Second, the rise in productivity due to an increase in capital makes job separation more costly. This lowers separations. Thus, capital investment magnifies the impact of the productivity shock on labor market variables through job creation and separation margins.

The incorporation of irreversible capital investment substantially improves the ability of the MP model to account for the observed fluctuations in unemployment and vacancies. The calibrated model generates cyclical fluctuations in the vacancy-unemployment ratio that are 1.6 times as large as predicted in the standard model. ${ }^{3}$ My model explains approximately $75 \%$ of the observed fluctuations in the vacancyunemployment ratio. This volatility decreases by $25 \%$ when job separation is exogenously determined. Thus, the model with endogenous separation generates more responses than one with exogenous separa-

\footnotetext{
${ }^{1}$ Although a large number of related studies has emerged to address this challenge, there has been a few studies which examine whether this failure of the MP model can be observed in other countries as well. See Burgess and Turon (2005) and Zhang (2008).

${ }^{2}$ Den Haan, Ramey and Watson (2000) demonstrate that interaction between capital investment and job destruction plays an important role in propagating shocks in the RBC model.

${ }^{3}$ The vacancy-unemployment ratio is the labor market variable that has attracted the most attention in the literature.
} 
tions.

Another important finding is that my model can generate the procyclicality of the vacancy rate, which the standard endogenous separation model often fails to generate (Shimer, 2005; Ramey, 2008; Mortensen and Nagypál, 2008). This different result arises because of the incorporation of capital investment. After incorporating capital investment, job creation becomes relatively more sensitive to productivity shocks than job separation. This generates the procyclicality of vacancies.

Mortensen and Nagypál (2007) argue that the MP model fails because of the large difference between labor productivity and the opportunity cost of employment. They show that incorporation of capital costs reduces this gap and generates larger labor market fluctuations. ${ }^{4}$ Yashiv (2006) and Silva and Toledo (2009) make a similar argument. They demonstrate that the incorporation of labor turnover costs improves the ability of the MP model to explain observed labor market variability. My paper is similar to this work, but provides an additional channel for productivity shocks to generate cyclical fluctuations of labor market variables. By explicitly incorporating firm's capital investment decisions, my model captures the effect of productivity shocks on capital, which affects both job creation and job destruction, and therefore magnifies the impact of productivity shocks on labor market outcomes.

The remainder of the paper is organized as follows. Section 2 describes the theoretical model. I develop an endogenous job separation matching model with irreversible capital investment. In Section 3, I calibrate the model parameters. Section 4 presents the results of quantitative statics exercise. I also study the role of endogenous job separation and discuss the sensitivity of the results to calibrated parameter values. Conclusions and suggestions for future research are presented in Section 5.

\section{The model}

Consider an economy consisting of a continuum of workers normalized to one and a large number of identical risk-neutral firms. Time is continuous. All agents are infinitely lived and maximize the present discounted value of their income with discount rate $r$.

A firm has only one job that can be either filled or vacant. One job is filled by one worker. ${ }^{5}$ A firm can produce output if its job is filled. If it is vacant, the firm produces no output and searches for a worker. A worker can be either employed or unemployed. If a worker is employed, he produces output and earns an endogenous wage $w$ but cannot search for other jobs. If he is not employed, he gets flow utility $z$ from non-market activity and searches for a job. When a firm with a vacant job and an unemployed worker

\footnotetext{
${ }^{4}$ See the version of "More on Unemployment and Vacancy Fluctuations" in the NBER Working Paper Series \#11692.

${ }^{5}$ In the standard search and matching model, each firm hires one worker and can post at most one vacancy (Mortensen and Pissarides, 1994; Pissarides, 2000). Pissarides (2000, Ch.3) considers a model of large firms in which each firm can employ many workers. He shows that a model with large firms has the same implication as the standard model, under the assumption that wage is determined through bargaining at the individual level.
} 
meet and start producing, it is said that job creation takes place. On the other hand, job separation takes place when a filled job separates and stops producing. When job separation takes place, the firm can either reopen a job as a new vacancy or withdraw from the labor market, while the worker becomes unemployed.

Production takes place in firm-worker pairs. Let the output of each firm be given by

$$
y=p x f(k)
$$

where $p$ is aggregate productivity, $x$ is match-specific idiosyncratic productivity, and $k$ is the amount of capital stock. The production function $f(k)$ satisfies $f^{\prime}(k)>0, f^{\prime \prime}(k)<0$, and the Inada conditions: $\lim _{k \rightarrow \infty} f^{\prime}(k)=0$ and $\lim _{k \rightarrow 0} f^{\prime}(k)=\infty$.

I assume that $x=1$ when a job is created. ${ }^{6}$ A randomly selected fraction $s$ of jobs break up for exogenous reasons and another randomly selected fraction $\lambda$ receive a productivity shock that changes each job's idiosyncratic productivity $x$ to some other value $x^{\prime} \in[0,1]$ according to the c.d.f $G\left(x^{\prime}\right)$. Facing the changed productivity $x$, the firm with a filled job chooses to produce at the new productivity or to close the job. Each firm chooses a reservation value $R$; if the firm-specific productivity falls below $R$, they destroy the job. The reservation productivity is chosen so as to maximize the firm's present value. When a filled job is destroyed, the firm leaves the labor market or reopens a new vacant job. The worker enters the unemployment pool and searches for another job. In order to hire a worker, a firm posts a vacancy at flow cost $\gamma$. Free entry drives the expected present value of an open vacancy to zero.

When a firm with a vacancy meets an unemployed worker and an employment contract is signed, the firm chooses its capital $k$ irreversibly and pays a capital installation $\operatorname{cost} C(k)$ and starts to rent capital at rate $r{ }^{78}$ The capital installation cost, $C(k)$, satisfies $C^{\prime}(k)>0$ and $C^{\prime \prime}(k) \geq 0$. This capital installation cost is incurred only once at the time of job creation. Capital depreciates continuously over time at a constant rate $\delta$.

The number of successful job matches per unit time is given by the matching function $M(u, v)$, where $u$ is the number of unemployed workers and $v$ is the number of vacancies. The matching function $M(u, v)$

\footnotetext{
${ }^{6}$ Under the assumption that firms know the technology that commands the highest productivity, all jobs are created at maximum idiosyncratic productivity $x=1$. Recently, Mortensen and Nagypál (2008) consider a generalized version of the MP model in which this assumption is relaxed.

${ }^{7}$ Acemoglu (1999) and Acemoglu and Shimer (1999a, 1999b) also consider irreversible capital investment in the search and matching model. Partially irreversible capital investment is empirically plausible.

${ }^{8}$ I assume that a firm invests in capital at the moment of job creation. I could set up the model so that the firm invests over time, not only at the beginning of the employment relationship. Thus, when an idiosyncratic productivity shock hits a firm, the firm is allowed to optimally invest in capital. However, in this setup, the role of capital irreversibility weakens. Furthermore, the extended model will be similar to the original MP model with capital (see Pissarides, 2000, Ch.2), and it is known that adding capital to the standard MP model does not help amplify productivity shocks (see Hagedorn and Manovskii, 2008). Therefore, in order to focus on the role of irreversible capital investment, I assume that a firm invests in capital at the beginning of the employment relationship.
} 
is continuous, twice differentiable, increasing in its arguments, and exhibits constant returns to scale. Define $\theta \equiv v / u$, which captures the tightness of the labor market. The rate at which a firm with a vacancy is matched with a worker per unit of time is $M(u, v) / v=M(1 / \theta, 1) \equiv q(\theta)$. Similarly, the rate at which an unemployed worker is matched per unit of time is $M(u, v) / u=\theta q(\theta)$. Because the matching function has constant-returns, $q(\theta)$ is decreasing and $\theta q(\theta)$ is increasing in $\theta$. In the steadystate, the inverse of the transition rates, $1 / q(\theta)$ and $1 / \theta q(\theta)$, are the expected duration of a vacancy and an unemployment, respectively. I also make the standard Inada-type assumptions on $M(u, v)$, which ensure that $\lim _{\theta \rightarrow \infty} q(\theta)=0, \lim _{\theta \rightarrow 0} q(\theta)=\infty, \lim _{\theta \rightarrow \infty} \theta q(\theta)=0$, and $\lim _{\theta \rightarrow 0} \theta q(\theta)=\infty$.

It is assumed that a wage is determined by Nash bargaining between the firm and the worker, where the worker has bargaining power $\beta \in(0,1)$.

\subsection{Value functions}

A filled job with idiosyncratic productivity $x$ and $k$ units of capital produces $p x f(k)$ per unit of time, and the employed worker is paid the wage $w(x)$ per unit of time. When an idiosyncratic shock hits the job at Poisson rate $\lambda$, the firm-specific productivity changes from its previous value $x$ to some new value $x^{\prime} \in[0,1]$, according to the c.d.f. $G\left(x^{\prime}\right)$. If the new value $x^{\prime}$ is larger than the reservation value $R$, the firm continues to produce at the new productivity. The firm stops producing if $x^{\prime}<R$. The job may be destroyed by an exogenous shock.

The value of a filled job, the present discounted value of expected profit from a filled job with idiosyncratic productivity $x$, is denoted by $J(x)$ and satisfies the following Bellman equation;

$$
r J(x)=p x f(k)-w(x)-(r+\delta) k+\lambda \int_{R}^{1} J\left(x^{\prime}\right) d G\left(x^{\prime}\right)+\lambda G(R) V-\lambda J(x)+s[V-J(x)],
$$

where $V$ is the value of a vacant job.

The value for an employed worker in a job with productivity $x$ is denoted by $W(x)$. It satisfies

$$
r W(x)=w(x)+\lambda \int_{R}^{1} W\left(x^{\prime}\right) d G\left(x^{\prime}\right)+\lambda G(R) U-\lambda W(x)+s[U-W(x)] .
$$

Although all jobs are created at maximum idiosyncratic productivity $x=1$, the expected profit of a new match will be different from $J(1)$, as generally defined in (1). This is due to the capital installation cost that is paid at the moment of job creation. Therefore, I introduce the notation $J^{n}$ for the expected profit of a new match to the firm. Then, the value of vacancy satisfies

$$
r V=-\gamma+q(\theta)\left[J^{n}-V-C(k)\right]
$$

Moreover, the value of an unemployed worker $U$ satisfies

$$
r U=z+\theta q(\theta)\left[W^{n}-U\right],
$$


where $W^{n}$ is the value of the worker at the moment of job creation.

Given an initial wage $w^{n}$, the initial value of a filled job and an employed worker respectively satisfy

$$
(r+\lambda+s) J^{n}=p f(k)-(r+\delta) k-w^{n}+\lambda \int_{R}^{1} J\left(x^{\prime}\right) d G\left(x^{\prime}\right)+[\lambda G(R)+s] V
$$

and

$$
(r+\lambda+s) W^{n}=w^{n}+\lambda \int_{R}^{1} W\left(x^{\prime}\right) d G\left(x^{\prime}\right)+[\lambda G(R)+s] U .
$$

The wages are determined through the Nash bargaining between a firm and a worker over the share of expected future joint income. I assume that, at the initial wage determination stage, the capital installation cost is considered as a loss in joint income. Because of this, there is a difference between the initial wage bargain and subsequent renegotiation. ${ }^{9}$ When a firm and a worker first meet, the payoff to the firm equals $J^{n}-V-C(k)$, because the firm incurs capital installation costs. Therefore, the starting wage is determined by the following equation

$$
w^{n}=\arg \max \left[W^{n}-U\right]^{\beta}\left[J^{n}-V-C(k)\right]^{1-\beta} .
$$

Once the match is formed, the firm no longer has to pay the capital installation cost. Thus, the renegotiated wage rate after an arrival of an idiosyncratic shock is given by

$$
w(x)=\arg \max [W(x)-U]^{\beta}[J(x)-V]^{1-\beta} .
$$

The solutions to these optimization problems, $w^{n}$ and $w(x)$, must satisfy the following first-order conditions,

$$
(1-\beta)\left[W^{n}-U\right]=\beta\left[J^{n}-V-C(k)\right],
$$

and

$$
(1-\beta)[W(x)-U]=\beta[J(x)-V]
$$

respectively.

When an idiosyncratic shock arrives, the firm can either continue to produce or close the job down. The optimal decision of the firm is to continue its production if $J(x) \geq V$, and to stop its production if $J(x)<V$. Hence, the reservation value $R$ is determined by the following condition,

$$
J(R)=V .
$$

In equilibrium, all profit opportunities from new jobs are exploited, so that the following free entry condition holds:

$$
V=0 .
$$

\footnotetext{
${ }^{9}$ This wage determination mechanism is adopted in most of search and matching models. See Pissairdes (2000, Ch.9) and Mortensen and Pissarides (1999).
} 
The optimal amount of capital $k$ is chosen by a firm to maximize the present-discounted value of its expected income at the moment of job creation. Thus, the optimal amount of capital $k$ satisfies

$$
\frac{d}{d k}\left[J^{n}-V-C(k)\right]=0 .
$$

The evolution of unemployment over time is given by

$$
\dot{u}=[\lambda G(R)+s](1-u)-\theta q(\theta) u \text {. }
$$

In the steady-state, the unemployment rate is determined by

$$
u=\frac{\lambda G(R)+s}{\theta q(\theta)+\lambda G(R)+s} .
$$

\subsection{Characterization of steady-state equilibrium}

The steady-state equilibrium is a profile $\left\{u, \theta, R, k, w^{n}, w(x), J^{n}, J(x), V, W^{n}, W(x), U\right\}$ which satisfies the Bellman equations (1), (2), (3), (4), (5) and (6), the wage equations (7) and (8), the reservation value condition (9), the free entry condition (10), the optimal capital investment condition (11), and the steadystate unemployment rate condition (12).

The free entry condition (10) together with (3) yields

$$
\frac{\gamma}{q(\theta)}=J^{n}-C(k)
$$

From (4), (7), (10), and (13), the value of unemployment $r U$ can be rewritten as

$$
r U=z+\frac{\beta \theta \gamma}{1-\beta}
$$

By substituting $J(x)$ and $W(x)$, given by (1) and (2), into (8), and by using the free entry condition (10), I obtain

$$
w(x)=\beta[p x f(k)-(r+\delta) k]+(1-\beta) r U .
$$

The wage is a weighted average of the flow values of the continuation and destruction of the job match. Substituting the value of unemployment (14) into the above equation, I get the following expression for the continuation wage

$$
w(x)=\beta[p x f(k)-(r+\delta) k]+(1-\beta) z+\beta \theta \gamma
$$

By substituting the wage equation (16) into (1) and imposing (10), I obtain

$$
(r+\lambda+s) J(x)=(1-\beta)[p x f(k)-(r+\delta) k-z]-\beta \theta \gamma+\lambda \int_{R}^{1} J\left(x^{\prime}\right) d G\left(x^{\prime}\right)
$$


Evaluating (17) at $x=R$ with (9) and subtracting this from (17), I obtain

$$
J(x)=\frac{(1-\beta) p f(k)(x-R)}{r+\lambda+s} .
$$

By substituting $J(x)$, given by (18), into (17), I obtain

$$
(r+\lambda+s) J(x)=(1-\beta)[p x f(k)-(r+\delta) k-z]-\beta \theta \gamma+\frac{\lambda(1-\beta) p f(k)}{r+\lambda+s} \int_{R}^{1}\left(x^{\prime}-R\right) d G\left(x^{\prime}\right) .
$$

I can derive the initial wage in a similar manner as the renegotiated wage. Substituting (5) and (6) into (7), and using (8), (10) and (14), I obtain the initial wage rate,

$$
w^{n}=\beta[p f(k)-(r+\delta) k-(r+\lambda+s) C(k)]+(1-\beta) z+\beta \theta \gamma .
$$

The initial wage differs from the renegotiated wage. Because the capital installation cost is incurred only at the creation of the match, it is shared between the worker and the employer. The initial wage is reduced by the worker's share of the capital installation investment $\operatorname{cost} \beta(r+\lambda+s) C(k)$. Once a job is created, the capital installation cost is sunk, and it no longer influences the wage renegotiated after future productivity shocks.

Substituting (10), (18), and (20) into (5) and subtracting (17) evaluated at $x=R$ from it, I get

$$
J^{n}=\frac{(1-\beta) p f(k)(1-R)}{r+\lambda+s}+\beta C(k) .
$$

Making use of (13) and (21), I derive the following equilibrium relationship between labor market tightness and the reservation productivity,

$$
\frac{\gamma}{q(\theta)}=(1-\beta)\left[\frac{p f(k)(1-R)}{r+\lambda+s}-C(k)\right] .
$$

I refer to this as the job creation condition. The job creation condition (22) states that the expected vacancy cost equals the firm's share of the expected net surplus from a new job match.

The shut-down threshold is derived by evaluating (19) at $x=R$ and by substituting (9) into it. I find

$$
p R f(k)-(r+\delta) k+\frac{\lambda p f(k)}{r+\lambda+s} \int_{R}^{1}\left(x^{\prime}-R\right) d G\left(x^{\prime}\right)=z+\frac{\beta \theta \gamma}{1-\beta} .
$$

I refer to this as the job destruction condition. The left-hand side of (23) is the marginal value of job continuation under the reservation value $R$. The first and second terms represent the current productivity gain, and the third term is the option value of retaining an existing job. On the right-hand side of (23) is the marginal value of destruction (or the marginal opportunity cost of continuation) of a job. The first and second terms together is the marginal value of an unemployed worker (see (14)). (23) says that the optimal reservation value $R$ should be set so as to equalize marginal benefit of continuation and destruction of the job. 
Lastly, I can derive the equilibrium level of capital investment as follows. The reservation value $R$ depends on the amount of capital $k$ since the amount of capital is determined at the time of job creation and the determination of job destruction is made later on. Hence, when a firm determines its amount of capital, the firm must take into account its effect on the reservation value $R$. Noting that the reservation value $R$ must satisfy (23) given $k$ and other endogenous variables, I can totally differentiate (23) with respect to $R$ and $k$ to obtain,

$$
\frac{d R}{d k}=-\frac{\left[p R f^{\prime}(k)-(r+\delta)+\frac{\lambda p f^{\prime}(k)}{r+\lambda+s} \int_{R}^{1}\left(x^{\prime}-R\right) d G\left(x^{\prime}\right)\right](r+\lambda+s)}{p f(k)[r+\lambda G(R)+s]} .
$$

From (10) and (21), I have

$$
J^{n}-V-C(k)=(1-\beta)\left[\frac{p f(k)(1-R)}{r+\lambda+s}-C(k)\right] .
$$

Using the above equation and (24), the condition for the optimal capital investment (11) can be expressed as

$$
\begin{aligned}
\frac{d\left(J^{n}-V-C(k)\right)}{d k} & =(1-\beta)\left[\frac{p f^{\prime}(k)(1-R)}{r+\lambda+s}-C^{\prime}(k)-\frac{p f(k)}{r+\lambda+s} \frac{d R}{d k}\right] \\
& =0
\end{aligned}
$$

which can be summarized as

$$
\frac{p f^{\prime}(k)}{r+\lambda+s}\left[1+\frac{\lambda \int_{R}^{1} x^{\prime} d G\left(x^{\prime}\right)}{r+\lambda G(R)+s}\right]-\frac{r+\delta}{r+\lambda G(R)+s}=C^{\prime}(k) .
$$

One can interpret the above optimal capital investment condition more easily by looking at the first line of (25). An increase in capital investment has two sorts of effects; the productivity in each period increases and the reservation productivity decreases (see the relation (24)). Since the expected life of the job increases, a decrease in the reservation productivity increases the value of the filled job. The first term and third term of the left-hand side of (25) capture the former effect and the latter effect respectively. The second term of the left-hand side of (25) captures the marginal cost of capital investment. Since the left-hand side of (26) is equivalent to the combination between the first and third terms of the bracket in the right-hand side of the first line of (25), condition (26) states that in equilibrium the optimal level of capital investment is such that the marginal cost of investment is equal to the expected gain from marginal increase in investment.

The second order condition for the determination of optimal capital investment level is given by

$$
\begin{aligned}
\frac{d^{2}\left(J^{n}-V-C(k)\right)}{d k^{2}}= & (1-\beta)\left\{\frac{p f^{\prime \prime}(k)}{r+\lambda+s}\left[1+\frac{\lambda \int_{R}^{1} x^{\prime} d G\left(x^{\prime}\right)}{r+\lambda G(R)+s}\right]-C^{\prime \prime}(k)\right\} \\
& +(1-\beta)\left\{\frac{d}{d R}\left[\frac{\frac{\lambda p f^{\prime}(k)}{r+\lambda+s} \int_{R}^{1} x^{\prime} d G\left(x^{\prime}\right)-(r+\delta)}{r+\lambda G(R)+s}\right] \frac{d R}{d k}\right\}<0,
\end{aligned}
$$


which implies

$$
\frac{p f^{\prime \prime}(k)}{r+\lambda+s}\left[1+\frac{\lambda \int_{R}^{1} x^{\prime} d G\left(x^{\prime}\right)}{r+\lambda G(R)+s}\right]-C^{\prime \prime}(k)+\frac{d}{d R}\left[\frac{\frac{\lambda p f^{\prime}(k)}{r+\lambda+s} \int_{R}^{1} x^{\prime} d G\left(x^{\prime}\right)-(r+\delta)}{r+\lambda G(R)+s}\right] \frac{d R}{d k}<0
$$

The system of equations (22), (23), and (26) determine endogenous variables $\theta, R$, and $k$. Given $\theta$ and $R$, equation (12) determines the steady-state equilibrium unemployment rate.

\section{Calibration}

In this section, I calibrate the model to match facts about the U.S. labor market. The following 14 parameters have to be determined: the discount rate $r$, the arrival rate of idiosyncratic shocks $\lambda$, the parameter in the the idiosyncratic productivity distribution $\xi$, the exogenous job separation rate $s$, the labor productivity parameter $p$, the production function parameter $\phi$, the capital depreciation rate $\delta$, the two capital investment cost function parameters $c_{0}$ and $\mu$, the two matching function parameters $m_{0}$ and $\alpha$, the vacancy $\operatorname{cost} \gamma$, the worker's bargaining power $\beta$, and the value of leisure $z$.

I choose the model period to be one month and set the discount rate to $r=0.004$ to match the annual real interest rate of approximately 5\%. I assume that the matching function is Cobb-Douglas,

$$
m(u, v)=m_{0} u^{\alpha} v^{1-\alpha},
$$

where $m_{0}$ is the matching constant and $\alpha$ is the matching elasticity with respect to unemployment. With this matching function, the job finding rate is $\theta q(\theta)=m_{0} \theta^{1-\alpha}$ and the vacancy filling rate is $q(\theta)=m_{0} \theta^{-\alpha}$. The elasticity parameter $\alpha$ is set to 0.5, as suggested by the estimates in Petrongolo and Pissarides (2001).

Following Pissarides (2009), I target a mean value of the vacancy-unemployment ratio of $\theta=0.72 .{ }^{10}$ Monthly transitions data from Shimer (2005) gives a mean value of 0.594 for the job finding rate and 0.036 for the job separation rate between 1960 and 2004. In order to pin down the scale parameter $m_{0}$, I combine the monthly job finding rate with the vacancy-unemployment ratio.

The production function is assumed to be Cobb-Douglas, $f(k)=k^{\phi}$, and $\phi$ is set equal to the conventional 0.33. The standard annual capital depreciation rate of $10 \%$ corresponds to a value of $\delta$ to 0.0084 per month. The cost function of capital investment is assumed to be strictly increasing and covex in the amount of capital. It is specified by $C(k)=c_{0} k^{1+\mu}$, where $c_{0}$ is a scale parameter and $\mu>0$. In the benchmark case, I assume that $\mu=1$. Thus, the cost function is quadratic. The aggregate productivity parameter $p$ is normalized to be one.

Silva and Toledo (2009) use evidence provided by Davis, Faberman, and Haltiwanger (2006) and Nagypál (2004) to determine the exogenous and endogenous components of the separation rate. They

\footnotetext{
${ }^{10}$ The sample mean for the vacancy-unemployment ratio in 1960-2006 is derived by using JOLTS data since December 2000 and the Help-Wanted Index adjusted to the JOLTS units of measurement before then.
} 
assume that endogenous job separation accounts for, on average, $35 \%$ of total separations. Since I target a total separation rate of 0.036 , I set the monthly exogenous separation rate at $s=0.0234$.

Following Mortensen and Pissarides (1994), I assume that the idiosyncratic productivity distribution $G$ is uniform in the range $[\xi, 1]$, so that

$$
G(x)=\frac{x-\xi}{1-\xi}
$$

Following Pissarides (2007) and Elsby and Michaels (2008), the parameter $\xi$ is chosen to match the monthly endogenous job separation rate. ${ }^{11}$ I choose the arrival rate of idiosyncratic shocks $\lambda$ so that the modelimplied elasticity of the separation rate with respect to productivity shock matches the data. Specifically, I use Shimer's (2005) results to set the elasticity of the separation rate with respect to productivity shock at $-1.97 .^{12}$

Haefke, Sonntag and van Rens (2009) document that wages of newly hired workers strongly respond to aggregate labor market conditions while the wages of workers in ongoing jobs does not fluctuate much. Following Elsby and Michaels (2008), I calibrate $\beta$ by targeting the elasticity of average wages of newly hired workers to be equal to approximately 0.8 , based on the results of Haefke et al. (2009). The main reason why I target the elasticity of newly hired workers' wages is that the flexibility of new hires' wages is relevant to the cyclicality of the job finding rate in a labor market with search frictions, since it affect firms' decisions to create jobs. Furthermore, rigid wages of workers in ongoing job relationships are at odds with the assumption of Nash wage setting that I employ in this paper.

Regarding the cost of posting a vacancy $\gamma$, Silva and Toledo (2007) report that per worker hiring costs $\gamma / q(\theta)$ account for 14 percent of quarterly worker compensation. In the context of the model, this implies a value of $\gamma$ approximately equal to 0.35 of the average worker's wage $\bar{w} \cdot{ }^{13}$ I now determine the value of non-market activity $z$. In calibrations of search and matching models, the choice of the parameter value $z$ is controversial. ${ }^{14}$ As suggested by Mortensen and Nagypál (2007) and Hall and Milgrom (2008), I set

\footnotetext{
${ }^{11}$ Following Pissarides (2007), I choose parameter in the idiosyncratic productivity distribution $\xi$. In contrast, Menzio and Shi (2009) and Zhang (2009) choose this parameter by targeting job tenure distribution, since the spread of an idiosyncratic productivity distribution affects the duration of employment.

${ }^{12}$ From Table 1 of Shimer (2005), the ratio of the standard deviations of job separation and labor productivity is 3.75 $(=0.075 / 0.020)$ and their correlation coefficient is -0.524 . These give a partial impact of productivity on the separation rate of -1.97 .

${ }^{13} \mathrm{I}$ want to equate the per worker hiring cost $\gamma / q(\theta)$ to $14 \%$ of quarterly wage, $0.14 \cdot 3 \cdot \bar{w}$, since there are 3 months per quarter. Then, the implied monthly job filling probability is given by $q=m_{0} \theta^{-\alpha}=0.825$. This implies that $\gamma=$ $0.14 \cdot 3 \cdot 0.825 \bar{w}=0.35 \bar{w}$.

${ }^{14}$ Shimer (2005) sets $z / \bar{w}$ equal to 0.4 in order to capture unemployment benefits. Hagedorn and Manovskii (2008) argue that Shimer's choice of the value of opportunity cost of employment is too low because it does not allow for the value of leisure, home production, as well as unemployment benefits. They calibrate the opportunity cost of employment and the worker's bargaining power to match the observed cyclical response of wages and average profit rate. Their results are $z=0.955$ and $\beta=0.052$. Mortensen and Nagypál (2007) criticize Hagedorn and Manovskii (2008) for using these parameters because these parameters yield workers a gain of $2.8 \%$ in flow utility by going from unemployment to employment.
} 
$z$ equal to the effective replacement rate $0.71 .{ }^{15}$ Finally, the scale parameter of the cost fucntion $c_{0}$ is obtained from the steady-state solutions of the model. The parameter values are summarized in Table $1 .^{16}$

Table 1: Calibrated parameter values

\begin{tabular}{llll}
\hline \hline Parameter & \multicolumn{1}{c}{ description } & value & \multicolumn{1}{c}{ source / target } \\
\hline$r$ & discount rate & 0.004 & data \\
$\lambda$ & exogenous rate of job separation & 0.074 & separations elasticity \\
$\xi$ & the lower support of $G$ & 0.509 & $35 \%$ of total separations \\
$s$ & the exogenous job separation rate & 0.023 & rest of separations \\
$z$ & value of non-market activity & 0.643 & Hall-Milgrom $(2008)$ \\
$m_{0}$ & scale parameter of Matching function & 0.700 & job finding rate \\
$\alpha$ & elasticity of matching function & 0.5 & Petrongolo-Pissarides $(2001)$ \\
$\beta$ & worker's bargaining power & 0.519 & Haefke et al. $(2009)$ \\
$\gamma$ & cost of posting a vacancy & 0.314 & Silva and Toledo $(2007)$ \\
$\phi$ & elasticity of production function & 0.333 & capital share $\approx 1 / 3$ \\
$\delta$ & capital depreciation rate & 0.008 & data \\
$c_{0}$ & cost function parameter & 1.01 & steady-state condition \\
$\mu$ & cost function parameter & 1.0 & quadratic cost function \\
\hline
\end{tabular}

The model solutions at these parameter values are shown in Table 2. Labor market tightness, the job finding rate of workers, and the separation rate are equal to their calibrated values. The initial wage, $w^{n}$, is 0.847 . The percentage gain in flow receipts when a worker accepts a job is substantial, $100(0.847-0.643) / 0.643=32 \%$.

\section{Business cycle volatility}

Shimer (2005) demonstrates that the standard MP model cannot generate enough cyclical volatility in key labor market variables in US data. Now I consider whether my model can solve this problem. In order to compute the impact of productivity shocks on equilibrium outcomes, I calculate the steady-state response to a $1 \%$ increase in aggregate productivity $p$. I examine the steady-state response as an approximation to

\footnotetext{
${ }^{15}$ Hall and Milgrom (2008) use utility parameter values based on the empirical literature on household consumption and labor supply and reports of the effective replacement ratio to estimate the value of $z$.

${ }^{16}$ The model can match the target moments, except the elasticity of wages of newly hired workers, which is slightly larger than the target moment. However, since I overstate the flexibility in wages of new hires relative to the target moment, if anything, I make a mistake on the side of generating less amplification.
} 
Table 2: Model solutions

\begin{tabular}{llcc}
\hline \hline Variable & description & solution & $p=1.01$ \\
\hline$\theta$ & labor market tightness & 0.720 & 0.752 \\
$R$ & reservation productivity & 0.592 & 0.589 \\
$k$ & average optimal capital investment & 2.074 & 2.101 \\
$u$ & unemployment rate & 0.057 & 0.055 \\
$v$ & vacancy rate & 0.041 & 0.042 \\
$\theta q(\theta)$ & job finding rate & 0.594 & 0.607 \\
$\lambda G(R)+\delta$ & separation rate & 0.036 & 0.035 \\
$\bar{p}$ & mean labor productivity & 0.796 & 0.802 \\
\hline
\end{tabular}

the dynamic response of the full stochastic version of my model. In the literature, it is well known that comparative static results are essentially equivalent to the dynamic response of the full stochastic version of the model. ${ }^{17}$

Table 2 reports the model's solutions when aggregate productivity $p$ rises by $1 \%$. Labor market tightness, the job finding rate, and the vacancy rate are procyclical, while the unemployment rate and the separation rate are countercyclical. Thus, the model is consistent with basic labor market facts.

Column (1) of Table 3 summarizes the main results from my model. In the endogenous separation model, the distribution of idiosyncratic productivity changes in response to productivity shocks; therefore, the mean labor productivity, $\bar{p}$, responds less than one-to-one to labor productivity shocks $p .{ }^{18}$ Therefore, I report the elasticities of relevant labor market variables with respect to labor productivity $p$ and the mean labor productivity $\bar{p}$. For comparison, column (2) shows the corresponding elasticities in the endogenous job separation model without capital investment. Following Mortensen and Nagypál (2007, 2008) and Pissarides (2009), I use empirical OLS regression coefficients as targets for these elasticities. ${ }^{19}$ These data moments are reported in the first column of Table 3. It is worth noting that these data moments are different from those in Shimer (2005). Assuming that productivity shocks are the only source of

\footnotetext{
${ }^{17}$ Shimer (2005) and Mortensen and Nagypál (2007) demonstrate that steady-state responses of the standard matching model with exogenous job separation are essentially equivalent to the dynamic response of the full stochastic version of it. Mortensen and Nagypál (2008) show that this argument holds in the matching model with endogenous job separation.

${ }^{18}$ As seen in Table 2, higher productivity reduces the reservation productivity. A decline in the reservation productivity reduces the mean of the idiosyncratic productivity of active jobs, so the observed increase in the mean labor productivity, $\bar{p}$, is less than the $1 \%$ increase in the labor productivity $p$.

${ }^{19}$ Mortensen and Nagypál (2007) argue that the empirical equivalent to the change in $x$ relative to changes in $y$ in the matching model in which adjustment of all endogenous variables takes place instantaneously or very fast, $\varepsilon_{x}, y$, is the OLS regression coefficient $\rho_{x y} \sigma_{x} / \sigma_{y}$, where $\sigma_{x}$ and $\rho_{x y}$ represent the standard deviation of $\ln x$ and the correlation between $\ln x$ and $\ln y$, respectively.
} 
fluctuations in labor market variables, Shimer (2005) uses the ratio of the standard deviation of the log of the relevant labor market variable to that of log productivity as targets. However, Mortensen and Nagypál (2007) argue that, because there is a small empirical correlation between productivity and labor market variables, assuming that productivity is the unique cause of labor market fluctuations is questionable. Thus, instead of considering the ratios of standard deviations, they gauge the consistency of the model by comparing the empirical OLS coefficients with the model's predictions.

Table 3: Predicted labor market responses to labor productivity and mean labor productivity

\begin{tabular}{|c|c|c|c|c|c|}
\hline Elasticity & Data & $\begin{array}{l}\text { Endo. separation } \\
\qquad+ \text { Capital } \\
\text { Benchmark (1) }\end{array}$ & $\begin{array}{l}\text { Endo. separation } \\
+ \text { No capital } \\
\text { (2) }\end{array}$ & $\begin{array}{c}\text { Exog. separation } \\
+ \text { Capital } \\
\text { (3) }\end{array}$ & $\begin{array}{l}\text { Exog. separation } \\
+ \text { No capital } \\
\text { (4) }\end{array}$ \\
\hline$\varepsilon_{\theta, p}$ & & 4.37 & 3.40 & 4.27 & 3.60 \\
\hline$\varepsilon_{R, p}$ & & -0.61 & -0.10 & - & - \\
\hline$\varepsilon_{k, p}$ & & 1.27 & - & 0.62 & - \\
\hline$\varepsilon_{u, p}$ & & -3.50 & -3.38 & -2.01 & -1.70 \\
\hline$\varepsilon_{v, p}$ & & 0.87 & 0.02 & 2.26 & 1.90 \\
\hline$\varepsilon_{f, p}$ & & 2.19 & 1.70 & 2.14 & 1.80 \\
\hline$\varepsilon_{s, p}$ & & -1.52 & -1.88 & - & - \\
\hline$\varepsilon_{\bar{p}, p}$ & & 0.77 & 0.96 & - & - \\
\hline$\varepsilon_{\theta, \bar{p}}$ & 7.56 & 5.66 & 3.55 & - & - \\
\hline$\varepsilon_{R, \bar{p}}$ & - & -0.79 & -0.10 & - & - \\
\hline$\varepsilon_{k, \bar{p}}$ & - & 1.64 & - & - & - \\
\hline$\varepsilon_{u, \bar{p}}$ & -3.88 & -4.53 & -3.54 & - & - \\
\hline$\varepsilon_{v, \bar{p}}$ & 3.68 & 1.13 & 0.02 & - & - \\
\hline$\varepsilon_{f, \bar{p}}$ & 2.34 & 2.83 & 1.78 & - & - \\
\hline$\varepsilon_{s, \bar{p}}$ & -1.97 & -1.97 & -1.97 & - & - \\
\hline
\end{tabular}

The incorporation of irreversible capital investment magnifies the impact of productivity shocks on labor market variables. In the literature, the elasticity of labor market tightness with respect to labor productivity is used to evaluate the performance of the model over the business cycle. The target value for this elasticity is 7.56 . In my model, the elasticity is 5.66 , which explains $75 \%$ of the observed volatility of labor market tightness. On the other hand, the standard matching model with endogenous job separation can explain only half of the observed volatility. Thus, the incorporation of capital investment amplifies the cyclical variation of labor market tightness.

Irreversible capital investment magnifies the impact of the productivity shocks on labor market tight- 
ness through the job creation and separation margins. When aggregate productivity rises, firms respond by investing in more capital, which further increases productivity. First, the higher productivity encourages firms to post more vacancies. Second, the rise in productivity, due to both the positive shock and the increase in capital, makes the job separation more costly. This lowers the reservation productivity and reduces separations. Thus, the impact of the aggregate productivity shock on job creation and separation is magnified due to irreversible capital investment. This leads to a larger volatility in labor market tightness.

Since I choose the parameter $\lambda$ to match the elasticity of the job separation rate to productivity, the computed response of the job separation rate to productivity is exactly equal to the one observed in the data. The model generates sufficient volatility in the job finding rate. While the model underpredicts the change in the vacancy rate relative to changes in productivity, it generates a large enough change in the unemployment rate. A striking difference between my model and the standard MP model is the cyclicality of the vacancy rate. A number of studies demonstrate that the matching model with endogenous job separation cannot generate the observed procyclicality of the vacancy rate (Shimer, 2005; Mortensen and Nagypál, 2007; Elsby and Michaels, 2008). While the MP model generates an acyclical vacancy rate, my model succeeds to generate a procyclical vacancy rate. This difference arises because job creation becomes relatively more sensitive to productivity shocks than job separation after incorporating capital investment.

\subsection{The role of endogenous job separation}

The incorporation of irreversible capital investment improves the ability of a matching model with endogenous job separation to explain the observed volatility of labor market variables. Now I assess the contribution of endogenous job separation by examining the exogenous separation version of my model. The details of this model can be found in Appendix.

In this model, the elasticity of labor market tightness with respect to productivity is

$$
\varepsilon_{\theta, p}=\frac{p f(k)}{p f(k)-(r+\delta) k-z-(r+s) C(k)} \frac{r+s+\beta \theta q(\theta)}{(r+s) \eta(\theta)+\beta \theta q(\theta)},
$$

where $\eta(\theta)=-\theta q^{\prime}(\theta) / q(\theta)$ is the elasticity of the matching function with respect to unemployment. Since the job finding rate equals $m_{0} \theta^{1-\alpha}$, the elasticity of the job finding rate with respect to productivity is given by $\varepsilon_{f, p}=(1-\alpha) \varepsilon_{\theta, p}$. The elasticity of unemployment with respect to productivity is $\varepsilon_{u, p}=$ $-(1-\alpha)(1-u) \varepsilon_{\theta, p}$. The elasticity of vacancies with respect to productivity is $\varepsilon_{v, p}=\varepsilon_{u, p}+\varepsilon_{\theta, p}$.

The basic parameter values are the same as before. Since all job separation is exogenous, I set the arrival rate of shocks $\lambda$ equal to zero and set the exogenous job separation rate $s$ to match the job separation rate. Thus, $s=0.036$. I also recalibrate parameters $z$ and $\gamma$ in order to maintain my calibration targets. The value of the worker's bargaining power $\beta$ is obtained from the steady-state solutions of the model. In this case, I set $z=0.75, \gamma=0.37$, and $\beta=0.52$. It is important to note that, for the numerical 
implementation of the model, $c_{0}$ can be eliminated from the equilibrium condition. Therefore, I set $c_{0}$ equal to one.

The model implied elasticities of relevant labor market variables are reported in column (3) of Table 3. For comparison, I also compute the corresponding elasticities in the standard matching model of Pissarides (2000), the exogenous job separation model without irreversible capital investment, using the same parameter values. The results are reported in column (4) of Table 3.

Endogenous job separations amplify the response of labor market tightness to productivity shocks. The elasticity of labor market tightness with respect to productivity shocks in the endogenous job separation model is $1.33(=5.66 / 4.27)$ times as larger as one in the exogenous job separation model. The reason of this result is that the former model produces countercyclical separations. Thus, in the boom, the rise in capital also reduces the reservation productivity, leading to lower endogenous job separation. This additional mechanism also helps amplify the change in labor market tightness relative to that of labor productivity.

\subsection{Sensitivity analysis}

Here I discuss the sensitivity of my results to my choice of parameter values. I study how my results vary with the flow value of unemployment $z$, the curvature parameter of the cost function $\mu$, and the elasticity parameter in the matching function $\alpha$. When I change these parameters, I also re-calibrate parameters $c_{0}, z, \beta, \gamma, \lambda$ and $\xi$ in order to main my calibration target values. In Table 4, I report the elasticities of relevant labor market variables with respect to the mean labor productivity unde the re-calibrated parameter values.

Table 4: Predicted labor market responses to productivity under an alternative calibration strategy

\begin{tabular}{|c|c|c|c|c|c|c|}
\hline Elasticity & Data & $\begin{array}{c}\text { Benchmark } \\
\text { (1) }\end{array}$ & $\begin{array}{c}z / \bar{w}=0.4 \\
(2)\end{array}$ & $\begin{array}{c}\mu=0.5 \\
(3)\end{array}$ & $\begin{array}{c}\mu=1.5 \\
(4)\end{array}$ & $\begin{array}{c}\alpha=0.456 \\
(5)\end{array}$ \\
\hline$\varepsilon_{\theta, \bar{p}}$ & 7.56 & 5.66 & 2.73 & 6.36 & 5.15 & 5.61 \\
\hline$\varepsilon_{R, \bar{p}}$ & - & -0.79 & -0.83 & -1.17 & -0.68 & -0.87 \\
\hline$\varepsilon_{k, \bar{p}}$ & - & 1.64 & 1.62 & 2.33 & 1.28 & 1.65 \\
\hline$\varepsilon_{u, \bar{p}}$ & -3.88 & -4.53 & -3.15 & -4.86 & -4.29 & -4.74 \\
\hline$\varepsilon_{v, \bar{p}}$ & 3.68 & 1.13 & -0.42 & 1.50 & 0.86 & 0.87 \\
\hline$\varepsilon_{f, \bar{p}}$ & 2.34 & 2.83 & 1.37 & 3.18 & 2.57 & 3.05 \\
\hline$\varepsilon_{s, \bar{p}}$ & -1.97 & -1.97 & -1.97 & -1.97 & -1.97 & -1.97 \\
\hline
\end{tabular}

First, I discuss the sensitivity of the results to my choice of the flow value of unemployment $z$. The value of $z$ is an important determinant of the overall volatility of the model in response to changes in productivity. 
Shimer (2005) demonstrates that a reasonably calibrated model fails to generate the observed volatility in the vacancy-unemployment ratio. ${ }^{20}$ Following Shimer (2005), I recalibrate $z$ by targeting the effective replacement rate of 0.4. The result is reported in column (2) of Table 4. The change of $z$ is crucial to the result. The elasticity of labor market tightness falls from 5.66 to 2.73. Furthermore, the model generates a countercyclical vacancy rate. These results are because the higher value of non-market activity increases the pro-cyclicality of profits.

Next, I consider the impact of the curvature parameter of the capital investment cost function $\mu$. The results are reported in columns (3) and (4) of Table 4 . Note that a smaller value of $\mu$ reduces the convexity of the cost function and leads to more capital investment. Since a higher capital investment generates more job creation and less job separation, the model generates a larger volatility of labor market variables. Recall the bench mark case, i.e., $\mu=1$, a one percentage point increase in mean labor productivity leads to an increase in labor market tightness of $5.66 \%$. With $\mu=0.5$ and $\mu=1.5$, the magnitude of the impact is $6.36 \%$ and $5.15 \%$, respectively. Thus, this sensitivity analysis suggests that a smaller value of $\mu$ yields a larger effect of productivity shock on labor market outcomes.

Lastly, I discuss the sensitivity of the results to my choice of the elasticity parameter in the matching function $\alpha$. Mortensen and Nagypál (2007) propose the method to estimate the elasticity parameter in the matching function $\alpha$. Following their method, I obtain $\alpha=0.456$. The column (4) reports the results under this parameter value. The change in $\alpha$ does not substantially alter the elasticities of relevant labor market variables with respect to the mean labor productivity.

\section{Conclusion}

In this paper, I study the role of capital investment in a search and matching model. I develop an endogenous job separation model in which a firm's decision for irreversible capital investment is endogenously determined. The incorporation of capital investment provides an additional channel for firms to respond to productivity shocks, significantly magnifying the response of labor market variables. This greater amplification of labor market outcomes arises because firms respond productivity shocks by adjusting the level of capital investment. The calibrated model generates cyclical fluctuations in the vacancy-unemployment ratio that are 1.6 times as large as in the standard MP model. Moreover, in contrast to the standard matching model with endogenous separations, my model produces the observed procyclicality of vacancies.

A number of important issues remain for future research. One is to simulate a full stochastic version of the endogenous job separation model with capital investment. Since comparative static results are essentially equivalent to the dynamic response of the full stochastic version of the model, I study the volatility of labor market variables in my model by calculating the steady-state response to labor productivity changes.

\footnotetext{
${ }^{20}$ Shimer (2005) finds the elasticity of labor market tightness with respect to labor productivity of 1.71.
} 
Although the main results will be the same, a fully simulated model yields richer business cycle properties of the model. Several studies have argued that the search and matching model with exogenous separation can match the empirically observed volatility of labor market variables if the wage setting mechanism generates a less procyclical wage. To consider an alternative wage setting mechanism in an endogenous job separation model is also a fruitful avenue for research.

\section{A Appendix}

In this Appendix, I develop the exogenous separation version of my model. The basic structure of the model is the same as that of the endogenous separation model in Section 2, but now it is assumed that all jobs are destroyed at the constant rate $s$ and firm-specific productivity is fixed at $x=1$.

Let the value of a firm with a filled job be $J$ and the value of a firm with a vacant job be $V$. Then, they are characterized by the following Bellman equations:

$$
r J=p f(k)-(r+\delta) k-w+s[V-J]
$$

and

$$
r V=-\gamma+q(\theta)[J-V-C(k)] .
$$

I now turn to a worker's side. Let $W$ denote the value of an employed worker. It satisfies

$$
r W=w+s[U-W]
$$

where $U$ is the value for an unemployed worker. The value of unemployment solves the following equation:

$$
r U=z+\theta q(\theta)[W-U] .
$$

Free entry implies that the value of posting a vacancy is zero. Thus, I have the following free entry condition:

$$
V=0
$$

The Nash bargaining solution implies that the wage is set so as to maximize the weighted product of the worker's and firm's net return from the match. That is,

$$
(1-\beta)(W-U)=\beta(J-V-C(k)),
$$

where $\beta \in(0,1)$ denotes the bargaining power of a worker.

A firm chooses the amount of capital $k$ to maximize the present-discounted value of its income at the moment of job creation. Thus, the optimal amount of capital $k$ satisfies

$$
\frac{d}{d k}[J-V-C(k)]=0
$$


By using above value functions (A1)-(A4), the free entry condition (A5), and the wage sharing rule (A6), I obtain the following equilibrium wage:

$$
w=\beta[p f(k)-(r+\delta) k-(r+s) C(k)]+(1-\beta) z+\beta \theta \gamma .
$$

Combining the free entry condition (A5) with (A2) yields

$$
\frac{\gamma}{q(\theta)}=J-C(k)
$$

Substituting the wage into (A1) and using (A8), I obtain the following job creation condition,

$$
\frac{\gamma}{q(\theta)}=\frac{(1-\beta)[p f(k)-(r+\delta) k-z]-\beta \theta \gamma}{r+s}-(1-\beta) C(k) .
$$

By using (A1), (A5), (A7) and the wage equation, I can get the following optimal capital investment condition

$$
\frac{p f^{\prime}(k)-(r+\delta)}{r+s}=C^{\prime}(k) .
$$

In the steady-state, the unemployment rate is determined by

$$
u=\frac{s}{s+\theta q(\theta)}
$$

The model is recursive. Under the assumptions of production and cost functions, equation (A10) gives the unique equilibrium level of capital investment $k$. With knowledge of $k$, the job creation condition (A9) gives the solution for labor market tightness $\theta$. And finally, with $\theta$, (A11) gives equilibrium unemployment. 


\section{References}

[1] Acemoglu, D., 1999. Changes in Unemployment and Wage Inequality: An Alternative Theory and Some Evidence, American Economic Review 89, 1259-1278.

[2] Acemoglu, D., Shimer, R., 1999a. Efficient Unemployment Insurance, The Journal of Political Economy 107(5), 893-928.

[3] Acemoglu, D., Shimer, R., 1999b. Holdups and Efficiency with Search Frictions, International Economic Review 40, 827-850.

[4] Burgess, S., Turon, H., 2005. Worker Flows, Job Flows and Unemployment in a Matching Model, Bristol Economics Discussion Papers 05/572, Department of Economics, University of Bristol, UK.

[5] Costain, J., Reiter, M., 2008. Business Cycles. Unemployment Insurance, and the Calibration of Matching models, Journal of Economic Dynamics and Control, 32, 1120-1155.

[6] Davis, S. J., Faberman, R. J., Haltiwanger, J. C., 2006. The Flow Approach to Labor Markets: New Data Sources and Micro-Macro Links, NBER Working Paper \#12167.

[7] Den Haan, W., Ramey, G., Watson, J., 2000. Job Destruction and Propagation of Shocks, American Economic Review 90, 482-498.

[8] Elsby, M., R., Michaels., 2008. Marginal Jobs, Heterogeneous Firms, \& Unemployment Flows, NBER Working Paper \#13777.

[9] Haefke, C., Sonntag, M., van Rens, T., 2009. Wage Rigidity and Job Creation, Kiel Working Papers 1504.

[10] Hagedorn, M., Manovskii, I., 2008. The cyclical behavior of equilibrium unemployment and vacancies revisited, American Economic Review, 98(4), 1692-1706.

[11] Hall, R. E., 2005. Employment Fluctuations with Equilibrium Wage Stickiness, American Economic Review 95, 50-65.

[12] Hall, R. E., Milgrom, P., 2008. The Limited Influence of Unemployment on the Wage Bargain. American Economic Review 98(4), 1653-74.

[13] Kennan, J., 2010. Private Information, Wage Bargaining and Employment Fluctuations, Review of Economic Studies 77, 633-664.

[14] Krause, M. U., Lubik, T. A., 2007. On-the-Job Search and the Cyclical Dynamics of the Labor Market, Discussion Paper Series 1: Economic Studies 2007, 15, Deutsche Bundesbank, Research Centre. 
[15] Menzio, G., Shi, S., 2009. Efficient Search on the Job and the Business Cycle, NBER Working Papers \#14905.

[16] Mortensen, D. T., Pissarides, C. A., 1994. Job Creation and Job Destruction in the Theory of Unemployment, Review of Economic Studies 61, 397-415.

[17] Mortensen, D. T., Pissarides, C. A., 1999. Job Reallocation and Employment Fluctuations. In: Woodford, M., Talyor, J. B.(Eds.), Handbook of Macro Economics vol.1, Elsevier Science, Amsterdam, pp.1171-1227.

[18] Mortensen, D. T., Nagypál, E., 2007. More on Unemployment and Vacancy Fluctuations. Review of Economic Dynamics 10(3), 327-347.

[19] Mortensen, D. T., Nagypál, E., 2008. Labor-Market Volatility in Matching Models with Endogenous Separations. Scandinavian Journal of Economics 109(4), 645-665.

[20] Nagypál, E., 2004. Worker Reallocation over the Business Cycle: The Importance of Job-to-Job Transitions. Mimeo. Northwestern University.

[21] Nagypál, E., 2007. Labor-market fluctuations and on-the-job search. Mimeo. Northwestern University.

[22] Petrongolo, B., Pissarides, C. A., 2001. Looking into the Black Box: A Survey of the Matching Function, Journal of Economic Literature 39, 390-431.

[23] Pissarides, C. A., 2000. Equilibrium Unemployment Theory 2ed. MIT Press, Cambridge, MA.

[24] Pissarides, C. A., 2007. The Unemployment Volatility Puzzle: Is Wage Stickiness the Answer?, CEP Discussion Paper No 839.

[25] Pissarides, C. A., 2009. The Unemployment Volatility Puzzle: Is Wage Stickiness the Answer?, Econometrica 77, 1339-1369.

[26] Ramey, G., 2008. Exogenous vs. endogenous separation. Mimeo. University of California, San Diego.

[27] Shimer, R., 2005. The Cyclical Behavior of Unemployment and Vacancies: Evidence and Theory, American Economic Review 95, 25-49.

[28] Silva, J. I., Toledo. M., 2007. Labor Turnover Costs and the Cyclical Behavior of Vacancies and Unemployment, Mimeo.

[29] Silva, J. I., Toledo. M., 2009. Labor Turnover Costs and the Cyclical Behavior of Vacancies and Unemployment, Macroeconomic Dynamics 13, 76-96. 
[30] Tasci, M., 2006. On-the-Job Search and Labor Market Reallocation, mimeo, University of Texas at Austin.

[31] Yashiv, E., 2006. Evaluating the performance of the search and matching model, European Economic Review 50(4), 909-936.

[32] Zhang, M., 2008. Cyclical Behavior of Unemployment and Job Vacancies: A Comparison between Canada and the United States, The B.E. Journal of Macroeconomics: Vol. 8 : Iss. 1 (Topics), Article 27.

[33] Zhang, M., 2009. Unemployment Insurance Eligibility, Moral Hazard and Equilibrium Unemployment. Mimeo, University of Toronto. 